\title{
Car cabin filters as a sampling devices to study bioaerosols using eDNA and microbiological methods
}

1 Kirsty V Hurley ${ }^{1}$, Laura Wharton ${ }^{1}$, Mike J Wheeler ${ }^{1}$, Carsten A Skjøth ${ }^{1}$, Christian Niles ${ }^{1}$, and Mary C Hanson ${ }^{1}$.

$2 \quad{ }^{1}$ Institute of Science and the Environment, University of Worcester, Worcester, Worcestershire, United Kingdom

3 * Correspondence:

4 Mary C Hanson

5 mary.hanson@worc.ac.uk

6 https://orcid.org/0000-0001-6028-5691

7 Keywords: bioaerosols, pollen, fungi, filters, environment, allergy

8 Acknowledgments Thanks is given to the University of Worcester for funding this research and to S. John and E.

9 Edwards for their technical assistance.

\section{Abstract}

The aim of this study was to examine whether bioaerosols could be isolated and quantified from used car cabin filters. Car cabin filters are widely available and can provide a vast untapped resource for sampling of bioaerosols in areas with enhanced air pollution. We developed a test system where we exposed car cabin filters to birch pollen under compressed air to represent airflow onto the filter. The flow of pollen within the test system was confirmed by microscopy and realtime PCR. Testing of extraction methods was performed on the most prevalent types of filters in UK cars and confirmed it was possible to extract and quantify viable fungi, birch pollen or proteins from car filters. The main challenge of their use is envisaged to be the lack of temporal resolution as car cabin filters are not routinely changed at intervals greater than one year, however the systematic recording of the different routes driven during the sampling interval has been enabled through the common use of GPS, smartphones or similar technologies. Car filters therefore provide substantial possibilities to monitor exposure of harmful bioaerosols in the polluted traffic regions defined by the road network. This method could also be applied to studying allergen exposure associated with bioaerosols and their delivery into the human respiratory system. These findings demonstrate that car cabin filters have the potential to be used to isolate and quantify a range of bioaerosols including pollen and fungi, as well as fractions of bioaerosols, such as proteins.

\section{Introduction}

Any biological component capable of being transported in the air is considered a bioaerosol and these include plant materials, such as pollen, or microbial material, such as fungal spores (Jones and Harrison, 2004, Douglas et al, 2017). Bioaerosols are significant because of their ability to affect human and crop health (e.g. see Kim et al. 2017, Brown and Hovmøller, 2002).

Human health concerns related to bioaerosols include respiratory problems, such as asthma, chronic obstructive pulmonary disease (COPD) and allergic rhinitis (e.g. Kim et al, 2017, D'amato et al., 2007). These are thought to be triggered by a range of factors, including chemical particulates and biological particles, which induce an immune response in predisposed individuals, however, the evidence for the involvement of bioaerosols such as pollen, is mixed. It has been shown that pollen is among the environmental factors causing increases in incidents of asthma requiring emergency treatment (Gleason et al. 2014; Gonzalez-Barcala et al. 2013; Ghosh et al. 2012). Contrary to this, Marchetti et al. (2017) found no association between pollen levels and asthma, indeed they reported a lower incidence of allergic rhinitis in areas with higher pollen levels, which was hypothesised to be related to increased rates of desensitization. A study on allergenic bioaerosols shows several orders of magnitude in the sensitization to Alternaria within major cities 
Given the variation within findings, further research is necessary to ascertain why the evidence is conflicting. It is known that the immune response triggered by allergens, such as pollen, is modulated by molecules, such as pollen-associated lipid mediators (PALMs) (Gilles et al 2009); There are several sources of lipids which may be associated with allergens; the pollen coat may contain lipids as part of its protective mechanism, lipids may also be bound to the allergens, and they may also originate from the pollen microbiome (Bublin et al 2014). The lipid profiles of the primary species of allergenic pollen have been documented and key lipid molecules associated with immune responses identified (Bashir et al 2013), however data on the effects of the environment on pollen lipid profiles are lacking. One possibility is that there may be environmental factors that modulate lipid production resulting in altered allergenicity. Aside from the potential effect of PALMs on the immune response, it has also been shown that allergen levels are not directly correlated to pollen levels (Buters et al. 2010, 2015). This suggests that current methods of counting pollen may not be the best indicator of allergenicity and associated symptoms. One possible reason is that current sampling methods do not provide the required temporal and spatial resolution to produce data to match the scale of the health events being studied. In the majority of studies, bioaerosol data is collected from static pollen monitoring stations which sample a given volume of air per unit of time. These may be sited in a variety of locations and the roofs university or hospital buildings are the most common locations (e.g. Sikoparija et al, 2017, Smith et al, 2014).

While static samplers are a valuable means of getting data, they are limited by collecting from a local environment with little or no spatial resolution. Repeatedly, studies have shown substantial spatial variation of aeroallergens in the urban environment (Werchan et al, 2017, Skjøth et al, 2013). Greater spatial resolution or sampling over larger areas instead of point based measurements would therefore be of benefit and are well aligned with recent findings on pollen and asthma (Pollock et al, 2017). Using vehicular filters would provide a means for mobile sampling without needing the modification of vehicles or samplers, and also provides access to an untapped data resource with the potential to be used for studies of the environmental effects on asthma epidemiology. With the increased interest in citizen science, there is the scope for public involvement in large scale health studies. The aim of this study was to examine whether bioaerosols and molecules associated with allergenicity, such as proteins, could be isolated and quantified from used car cabin filters using standard methods.

\section{Materials and Methods}

\section{$2.1 \quad$ Test system}

85

In order to approximate bioaerosol transport through a car ventilation system within a laboratory, a test system was designed that included a source of compressed air, pollen and a car cabin air filter (CAF). The mechanism of cabin air ventilation is dependent on the car model, but generally has a heating function, which may or may not be associated with air conditioning. As car cabin filters only receive air flow when turned on, this system is representative of a functioning cabin ventilation system. The test system comprised of a PVC tube of $1000 \mathrm{~mm}$ length by $110 \mathrm{~mm}$ diameter. The leading 
$100 \mathrm{~mm}$ and installed at the open end of the tube and held in place using an open-centered rubber seal. Birch pollen grains were weighed to $0.025 \mathrm{~g}$ and placed on a platform inside the tube, by the compressed air entry port. The number of pollen grains present in $0.025 \mathrm{~g}$ pollen was calculated by suspension in $1 \mathrm{~mL}$ sterile distilled $\mathrm{H}_{2} \mathrm{O}$, thorough vortexing and counting using a haemocytometer at $100 \times$ magnification. Counts were repeated six times.

Activation of the compressed air distributed the pollen throughout the test tube and resulted in pollen impaction onto the CAF. The air flow was maintained for 10s, after which the compressor was stopped prior to removal of the filter from the test system for genomic DNA extraction. The test system was operated at $20^{\circ} \mathrm{C}$ and $50 \%$ humidity.

Initial experiments determined the proportion of pollen impacting on the filter in the test system. For this, one 1.5mL tube was located in the centre of an expanded CAF sample. Expanding the CAF to remove the concertina structure provided a flat surface through which air could flow, while supporting the $1.5 \mathrm{~mL}$ tube in the centre to collect pollen. Birch pollen was then run through the system as described and the pollen grains collected in the $1.5 \mathrm{~mL}$ tube were suspended in $100 \mu \mathrm{L}$ water and, following a vigorous vortex to remove pollen grains adhered to the sides of the tubes, a $20 \mu \mathrm{L}$ aliquot counted on a haemocytometer at $100 \times$ magnification. This was repeated in triplicate for each type of filter and the mean level of pollen hitting the filter was calculated from the amount of pollen collected in each tube with each tube opening representing $1 / 100^{\text {th }}$ of the surface area of the filter.

\subsection{DNA extraction}

Using the test system, the potential to extract pollen DNA from two of the three major types of car filter in the UK (activated charcoal/carbon and particulate) was examined. The third major type of CAF relies on electrostatic charge and this was not replicated here. The CAFs used in this test system were for a Ford Focus. In this instance the filters used were manufactured by Crosland (Euro Car Parts Ltd. Middlesex, UK).

A comparison of DNA extraction from the two filter types exposed to pollen in the test system was performed. The first method of DNA extraction tested followed the method of Radosevich et al. (2002) with the following amendments; $1 / 4$ of the $100 \mathrm{~mm}$ CAF sample was cut into approximate $1 \mathrm{~cm}$ strips and placed in a $50 \mathrm{~mL}$ centrifuge tube with $43 \mathrm{~mL}$ PBS-T (0.01M Phosphate buffer, $0.0027 \mathrm{M} \mathrm{KCl}, 0.137 \mathrm{M} \mathrm{NaCl}_{2}, 0.05 \%$ Tween 20 ). Tubes were vortexed vertically for $90 \mathrm{~s}$ in a Vortex Genie 2 (Scientific Industries, Inc., New York, USA), a Q Series ultrasonic water bath (Ultrawave, Cardiff, UK) was used to sonicate the samples for 10 minutes, maximum power at $22^{\circ} \mathrm{C}$, prior to a $5 \mathrm{~s}$ vortex. As per Radosevich et al (2002) the suspension was poured into clean $50 \mathrm{~mL}$ centrifuge tubes and the process repeated for a second wash of the filter strips using $25 \mathrm{~mL}$ PBS-T. Centrifugation was performed on both collected sample washes at room temperature for $30 \mathrm{~min}$ at $1400 \times \mathrm{g}$. Pellets for each sample were combined in $1.5 \mathrm{~mL}$ PBS-T and centrifuged at $16000 \times \mathrm{g}$, 8 min. Pellets were suspended in $200 \mu \mathrm{L}$ PBS-T to provide a 'filter concentrate'. DNA extraction was performed on $100 \mu \mathrm{L}$ of the filter concentrate using a DNeasy PowerSoil DNA isolation kit following the manufacturer's instructions (Qiagen, Hilden, Germany) with the following modification of the homogenisation step to 60s at speed 6.5 in a FastPrep (MP Biomedicals, California, USA).

The second method of DNA extraction used the DNeasy PowerMax Soil DNA isolation kit (Qiagen, Hilden, Germany). extraction following the manufacturer's instructions.

\subsection{Real-time PCR on lab test samples}

Genomic DNA extracted and clean-up from the CAFs by the different methods detailed were amplified by real-time PCR using primers for birch BP8 for 5'-ACGATCGAGTTTTCATCAAACAAA-3' and BP8 rev 5'GACCTTATTGTCTTCACGGTCCTT-3' (Müller-Germann et al. 2015). Reactions consisted of 1 x qPCRBIO SyGreen Blue Mix Separate-ROX (PCR Biosystems, London, UK), $0.15 \mu \mathrm{M}$ each primer, $8 \mu \mathrm{L}$ DNA and molecular grade $\mathrm{H}_{2} \mathrm{O}$ to $20 \mu \mathrm{L}$ final volume. Cycling was performed in a Lightcycler 480 (Roche Diagnostics, Burgess Hill, UK) using Axygen 96 well plates (Corning, New York, USA). Parameters were $95^{\circ} \mathrm{C}$ for 5 mins followed by 40 cycles of $95^{\circ} \mathrm{C} 5 \mathrm{~s}, 60^{\circ} \mathrm{C} 30 \mathrm{~s}$ 
followed by a melt curve of $95^{\circ} \mathrm{C} 1 \mathrm{~min}, 40^{\circ} \mathrm{C} 1 \mathrm{~min}, 60^{\circ} \mathrm{C} 1 \mathrm{~s}$, continuous to $95^{\circ} \mathrm{C}$ with fluorescence measured five times

141 for every degree increase. Standard curves were generated from the DNA extracted from $0.25 \mathrm{~g}\left(2.5 \times 10^{8}\right)$ birch pollen

142 grains serially diluted (10-fold) to produce a series of standards covering the equivalent of $10^{8}$ to $10^{3}$ pollen grains.

\subsection{Car filters}

Six car cabin filters collected during routine services by a qualified mechanic and stored at $-20^{\circ} \mathrm{C}$ prior to analysis. A $5 \times 5 \mathrm{~cm}$ subsample was cut from each filter into $1 \mathrm{~cm}$ strips and placed in a $50 \mathrm{~mL}$ centrifuge tube and processed via the adapted method of Radosevich et al (2002). Filtrate was examined for the presence of pollen and microorganisms at $\times$ 400 magnification and DNA extraction using the DNeasy PowerSoil DNA extraction kit was performed as described previously.

To examine the effects of any inhibitors present in the resultant DNA extracts, two approaches to cleaning up the DNA prior to PCR were taken; diluting the DNA and a commercial DNA clean-up method, DNeasy PowerClean ${ }^{\circledR}$ Cleanup kit (Qiagen, Hilden, Germany). This gave a total of four DNA treatments; undiluted (neat), 1 in 10 dilution, 1 in 100 dilution and the Cleanup kit. All dilutions were performed in to molecular grade $\mathrm{H}_{2} \mathrm{O}$ and the DNeasy PowerClean ${ }^{\circledR}$ Cleanup kit purification was performed according to the manufacturer's instructions. For each clean-up method $50 \mu \mathrm{L}$ of the DNA extracts was used from both types of filters and DNA extraction methods, and all experiments were repeated in triplicate. The amount of DNA present (ng $\mu \mathrm{L}^{-1}$ ) in the filtrate was quantified using a Nanodrop 2000 (ThermoFisher Scientific, Waltham, USA).

After DNA extraction the quantity of birch pollen on the car cabin filters was determined by qPCR as described previously using the method of Müller-Germann et al. (2015) with a standard curve generated from a known quantity of birch pollen grains (Allergon, ThermoFisher Scientific, Waltham, USA) determined by haemocytometry Total eukaryotic DNA was also amplified, using primers ITS86F/ITS4 (ITS86F; 5'- GTGAATCATCGAATCTTTGAA-3', ITS4; 5'TCCTCCGCTTATTGATATGC-3') and qPCRBIO SyGreen Blue Mix Separate-ROX (PCR Biosystems, London, UK) following the method and cycling parameters detailed in Op De Beeck et al (26). Instead of quantification against a standard curve, quantification cycles (Cq) were used to compare the effects of inhibitors on the amplification of DNA.

Two filters were selected at random and $100 \mu \mathrm{L}$ of the extracted filtrate was diluted to 1 in 10,1 in 100 and 1 in 1000 in Maximum Recovery Diluent (Oxoid Ltd. Cheshire, UK). From each concentration $100 \mu \mathrm{L}$ aliquots were spread onto Nutrient agar and Rose Bengal agar (with chloramphenicol 100 $\mathrm{mg} \mathrm{L}^{-1}$ ) (Oxoid Ltd. Cheshire, UK) in triplicate to measure total viable count and fungi respectively. Nutrient agar plates were incubated for four days at $30^{\circ} \mathrm{C}$ and Rose Bengal plates for six days at $20^{\circ} \mathrm{C}$ before the number of colony forming units (CFU) were counted.

\subsection{Protein concentration}

A $100 \mu \mathrm{L}$ aliquot from each filtrate was centrifuged at $1400 \mathrm{~g}$ for $10 \mathrm{~min}$ to pellet debris. The supernatant was then centrifuged at $17000 \times g$ for 10 min to pellet proteins. Total protein concentration in the supernatant was measured by bicinchoninic acid assay (BCA) using a Pierce ${ }^{\mathrm{TM}}$ BCA protein assay kit (ThermoFisher Scientific) following the manufacturers' 96 well microplate instructions. Bovine Serum Albumin (BSA) was used as a standard from $2 \mathrm{mg} \mathrm{mL}^{-1}$ and protein concentration was measured at 562nm absorbance.

\subsection{Statistics}

To compare the abundance of bacteria and fungi on car filters, CFU from each type of filter were log transformed and compared by t-test. The difference between DNA extraction methods and type of car filters was examined by MannWhitney $\mathrm{U}$ tests on untransformed data. Two-way ANOVA tested the effect of PCR inhibition on fungal and pollen amplification. Pollen amounts were calculated using the fit points method of quantitative analysis, with the threshold of background fluorescence set at three times the standard deviation. Protein concentration was interpolated from the BSA standard curve generated by 4-parameter logistic regression. All data was analysed in GraphPad Prism v7.0 (GraphPad 
Software, Inc. California, USA) except for qPCR analysis which was conducted using the proprietary LightCycler 480 software (Roche Diagnostics, Burgess Hill, UK).

\section{$190 \quad 3 \quad$ Results}

\subsection{Test System Validation}

Haemocytometer counts showed a mean of $2.5 \times 10^{7}$ birch pollen grains in $0.025 \mathrm{~g}$. In the test system the approximate

\subsection{DNA Extraction}

Quantitative PCR for birch pollen on filters from the test system had an efficiency of 1.89 and slope of -3.63 . The amount of birch pollen detected on carbon and particulate filters extracted using the DNeasy PowerMax DNA isolation kit (Qiagen, Hilden, Germany) was lower than on both types of filters extracted with a sonication step, and a Mann-Whitney $\mathrm{U}$ test showed the difference was significant $(\mathrm{U}=0, \mathrm{P}<0.01)$. There was no difference in the median amount of birch DNA detected on either type of filter $(\mathrm{U}=2.5, \mathrm{P}=0.5)$.

204

205

\subsection{Car filters}

Both bacteria and fungi were cultured from the two filters tested in similar quantities (figure 1). The mean total viable count and fungal count were both $3.3 \times 10^{3} \mathrm{CFU}$ on a $5 \times 5 \mathrm{~cm}$ segment of filter. This confirms the existence of viable microorganisms on the car cabin filters. Pollen grains and microorganisms were visible in filtrates at x400 magnification. Overall there was no significant difference between the total viable count and fungal counts $(\mathrm{t}=0.532$, $\mathrm{df} 2, \mathrm{P}=0.65)$ suggesting fungi comprise the majority of microorganisms present.

The amount of DNA in the filtrates ranged from 48.8 to 342.3ng $\mu \mathrm{L}^{-1}$. Quantitative PCR for Birch pollen on car filters had an efficiency of 1.999 and slope of -3.323 . Birch pollen was present on all except one of the car filters in undiluted DNA extracts. Diluting the DNA ten-fold subsequently resulted in the detection of a small quantity of birch pollen on the previously negative filter (figure 2). When the dilution factors were taken into account the maximum amount of birch pollen detected on a $5 \mathrm{~cm}^{2}$ filter was $2.83 \times 10^{5}$ grains and the minimum was $2.38 \times 10^{3}$ grains. Greater counts were calculated on five out of the six filters tested once dilution was considered, however when counts were transformed by $\log _{10}(\mathrm{Y}+1)$, this was shown to be insignificant by one-way ANOVA $(\mathrm{F}=1.645, \mathrm{P}=0.23)$.

The filters from cars driven on roads all generally followed the same trend of Cq results when amplified using eukaryotic ITS primers. Undiluted samples showed the lowest Cq values and therefore the greatest DNA quantity, while the 1 in 100 dilutions showed the highest, with the 1/10 dilution and cleaned-up DNA falling in between (figure 3). The mean Cq of undiluted samples was 22.40 (SD 3.272) and of cleaned-up DNA was 24.35 (SD 1.953) while the 1/10 and 1/100 samples had Cq values of 25.42 (SD 1.535) and 29.88 (SD 1.640) respectively and the differences between these was significant ( $\mathrm{F}=186.9$, df $3, \mathrm{P}<0.0001$ ). There was no uniform increase between the undiluted, 1/10 and 1/100 in any of the filters tested, which may indicate inhibitory effects. Given that two way ANOVA showed significant differences in Cq values from the filters from different vehicles $(\mathrm{F}=57.16$, df $5, \mathrm{P}<0.0001)$, it is likely that both eukaryotic DNA quantity and inhibitory molecules are unique to each filter tested. 


\subsection{Protein concentration}

Total protein concentration was extrapolated from the BSA standard curve and ranged from 0.42 to $1.47 \mathrm{mg} \mathrm{mL}^{-1}$ across the six car filters (table 1). The difference in protein concentration was significant between the filters $(\mathrm{F}=58.62, \mathrm{p}$ $<0.0001)$

\section{Discussion}

Using filters that extract bioaerosols from car cabins it was possible isolate pollen, fungi and bacteria by culturing and through extraction of genomic DNA. The amount of DNA extracted from filters was comparable to amounts collected by Radosevich et al (2002) from air filters. Using car cabin filters provides a new, mobile, approach to air sampling which will be useful in ecological and public health studies. Car cabin filters have previously been used to study particulates (Hong Park et al 2010, He et al 2016, Wong et al 2011) but this is the first report of their use for the study of bioaerosols that we are aware of. The results of the test system demonstrate that not all bioaerosols entering into the system are evenly distributed on the car filter or within the tube. This efficiency is most likely related to aerosol dynamics in the ventilation system and will be specific to each car model.

When a test system was used to assess DNA extraction methods, it was found that inclusion of a sonication step provided greater DNA yields than a standard DNA extraction kit based on bead beating. This supports the findings of Luhung et al (2015) who found that high temperature sonication was essential for increasing the amount of DNA extracted from environmental samples collected on filters. The time and temperature used here were shorter and lower respectively than the optimum found by Luhung et al (2015), but the mean amount of birch pollen quantified from filters by qPCR was slightly greater than the mean amount of birch impacting on the filter in the test system as determined by microscopy.

The test system itself could provide a valuable means of examining the collection of bioaerosols. More complex systems have been used in the examination of pollutants (Muala et al 2014)) and the test system described here could be further developed for studies of bioaerosols within controlled environments. In translating the test system to samples collected from cars it was expected that road samples would contain particles that could inhibit PCR. PCR inhibitors are prevalent in environmental samples and can take many forms, such as metal ions (Scharder et al. 2012; Combs et al 2015). However, there was no inhibition observed in this study. The maximum DNA levels were extracted from the neat, unmodified samples. Using a commercially available clean up kit resulted in DNA levels similar to that of a ten-fold dilution of neat DNA. Diluting the DNA sample itself is sometimes sufficient to decrease the levels of inhibitors to allow PCR amplification when there is sufficient DNA present for detection, however this was not observed here.

Although microscopic examination of samples remains the most widely used method of bioaerosol analysis, DNA based methods are gaining ground and can provide a greater depth to the data obtained than basic quantification. For example it has been possible to determine the structure of bioaerosol populations at different time points (Lee et al 2010) and in different locations (Després, et al 2007) using real time PCR and restriction fragment length polymorphism (RFLP) analysis. There are certain considerations to air sampling for molecular analysis, such as the substrate on which the sample is collected. This can vary dependent on the type of air sampler used. Common samplers will impact particles onto coated glass slides for microscopic examination while other methods impact into tubes or wells allowing subsequent analysis. It is also possible to collect samples directly onto agar plates, a method which has obvious advantages for the study of bacteria and fungi, while other samplers collect on to filters (Juozaitis et al, 1994; Radosevich et al 2002).

It was possible to determine total protein concentration from the filters, suggesting that the quantity of airborne allergens could be determined if appropriate methods, such as enzyme linked immunosorbent assays (ELISA), were applied. Most common bioaerosol allergens are proteins and it has been possible to quantify these from air samples collected on filters using specialised sampling devices, such as the case of Bet v 1 (birch allergen) in a European wide study (Buters et al. 2010).

An exploration of whether standard methods for extracting lipids by gas chromatography-flame ionization detection could be applied to used car filters has been performed (unpublished data). The results suggest there may be potential to extract 
lipids from car air filters, as peaks were obtained which may, in theory, represent iso-fatty acids. Bashir et al (2013) identified the main lipids in pollen (fatty acids, aliphatic hydrocarbons, fatty alcohols, sterols and terpenes) and bacteria and fungi will present different fatty acid profiles also. It has been demonstrated that it is possible to use lipid profiling to distinguish between gram positive and negative bacteria (Synder et al. 1990) and to help identify bacteria to species level (Torkko et al. 2003) and the practice of using lipids to monitor environmental impact on microorganisms is not new (Willers et al 2015). To contribute to understanding of the role of the environment on allergenicity of airborne particles, future work in this area should focus on the lipids from pollen and the associated microbiomes, as well as fatty acids acting as PALMs. To achieve this, improvement of the methods used to study lipids from complex air samples will be needed.

The ability to identify species, allergens and lipids in bioaerosol samples will undoubtedly contribute to an improved understanding of airborne allergens as causative agents of respiratory conditions. In combination with improved sampling resolution, this will drive towards more personalised risk projections for predisposed individuals. One of the greatest challenges in achieving an improvement in sampling resolution is having resources to monitor large areas at a local scale. Mobile air sampling offers this but one of its limitations is sampling a large enough volume of air to obtain sufficient biological material to analyse. Traditional methods of air sampling, such as volumetric air samplers of the Hirst design (Hirst, 1952), provide a good throughput of air and collect sufficient material, but are limited by being fixed in one location, while existing mobile sampling methods such as personal air samplers process a smaller volume but offer benefits of localised data. Success has been achieved in designing studies using personal air samplers (Agranovski et al 2017; Tolchinsky et al 2011) and, with the demand for advances in both meteorological and biological forecasting, recent technologies such as unmanned aerial vehicles (UAVs or 'drones'), are emerging as potential sources of data through the collection of bioaerosols in the atmosphere (e.g. Savage et al, 2012) and collected geophysical data (Niedzielski et al, 2017). Collecting biological material with drones or other mobile units such as cars has the potential to provide data to support forecasting pollen distribution and the spread of plant disease but the means with which the material is collected is not yet ergonomic. Although these technologies advance air sampling techniques there are limited studies which have utilised motor vehicles as potential sampling tools (West and Kimber 2014). The results presented in this study shows that modern motor vehicles provide a resource that can be tapped into with respect to the knowledge of how bioaerosols are distributed in the environment.

In conclusion there is the potential to utilise car cabin air filters as a means of studying the abundance and epidemiology of bioaerosols at a localised level. The benefits of this technique are abundance of samples, low cost, mobility, greater resolution providing constraints are met (routes recorded etc.) and can act as an adjunct to existing methods of analysis. However, there are certain limitations, which would have to be considered in study design. These include; variations in air flow between vehicles and different distances travelled, how recording routes driven is performed (spatial), and the infrequent assessment of data (lack of temporal effects). Providing these limitations are addressed in the design of future studies, there is scope for the incorporation of mobile air sampling into health and agricultural research.

\section{$5 \quad$ References}

Agranovski, I.E., Usachev, E.V., Agranovski, E. \& Usacheva, O.V. 2017, "Miniature PCR based portable bioaerosol monitor development", Journal of Applied Microbiology, 122, (1), pp. 129-138.

Bashir MEH, Lui JH, Palnivelu R, Naclerio RM, Preuss D (2013) Pollen Lipidomics: Lipid Profiling Exposes a Notable Diversity in 22 Allergenic Pollen and Potential Biomarkers of the Allergic Immune Response. PLoS ONE 8(2): e57566. doi:10.1371/journal.pone.0057566 
geographic location and time in season. Journal of Allergy and Clinical Immunology. 2015 Jul; 136(1):87-95.e6. doi: 10.1016/j.jaci.2015.01.049. PubMed PMID: 25956508.

Buters, JTM, Weichenmeier I, Ochs S, PuschG, Kreyling W, Boere AJF, Schober W, Behrendt, H. The allergen Bet v 1 in fractions of ambient air deviates from birch pollen counts. Allergy 2010; 65:850-858

Brown, J. K. M. and Hovmøller, M. S.: Aerial Dispersal of Pathogens on the Global and Continental Scales and Its

Impact on Plant Disease, Science, 297(5581), 537-541, doi:10.1126/science.1072678, 2002.

Combs LG, Warren JE, Huynh V, Castaneda J, Golden TD, Roby RK. The effects of metal ion PCR inhibitors on results obtained with the Quantifiler(®) Human DNA Quantification Kit. Forensic Science International: Genetics. 2015 Nov; 19:180-189. doi:10.1016/j.fsigen.2015.06.013. Epub 2015 Jul 15. PubMed PMID: 26240969.

D’amato, G., Cecchi, L., Bonini, S., Nunes, C., nnesi-Maesano, I., Behrendt, H., Liccardi, G., Popov, T. and Van Cauwenberge, P.: Allergenic pollen and pollen allergy in Europe, Allergy, 62(9), 976-990, 2007. aerosol particles in urban, rural, and high-alpine air by DNA sequence and restriction fragment analysis of ribosomal RNA genes. Biogeosciences, 4 pp.1127-1141 of bioaerosols from intensive farming, International Journal of Hygiene and Environmental Health, doi:10.1016/J.IJHEH.2017.10.019

Ghosh D, Chakraborty P, Gupta J, Biswas A, Roy I, Das S, and Gupta-Bhattacharya S. (2012) Associations between pollen counts, pollutants, and asthma-related hospital admissions in a high-density Indian metropolis. Journal of Asthma. 49(8):792-9.doi: 10.3109/02770903.2012.716473. PubMed PMID: 22978307.

Gilles S, Mariani V, Bryce M, Mueller M J, Ring J, Behrendt H, Jakob T, and Traidl-Hoffmann C. (2009). Pollen allergens do not come alone: pollen associated lipid mediators (PALMS) shift the human immune systems towards a TH2-dominated response. Allergy, Asthma and Clinical Immunology. 5:3 https://doi.org/10.1186/1710-1492-5-3

Gleason JA, Bielory L, and Fagliano JA. (2014). Associations between ozone, PM2.5, and four pollen types on emergency department pediatric asthma events during the warm season in New Jersey: a case-crossover study. Environmental Research. 132:421-9 doi: 10.1016/j.envres.2014.03.035. PubMed PMID: 24858282.

Gonzalez-Barcala FJ, Aboal-Viñas J, Aira MJ, Regueira-Méndez C,Valdes-Cuadrado L, Carreira J, Garcia-Sanz MT, and Takkouche B. (2013) Influence of pollenlevel on hospitalizations for asthma. Archives Environmental Occupational Health. 68 (2):66-71. doi: 10.1080/19338244.2011.638950. PubMed PMID: 23428055

He, X., Brem, B.T., Bahk, Y.K., Kuo, Y. and Wang, J. 2016, Effects of relative humidity and particle type on the performance and service life of automobile cabin air filters, Aerosol Science and Technology, vol. 50, no. 6, pp. 542-554.

Heinzerling, L. M., Burbach, G. J., Edenharter, G., Bachert, C., Bindslev-Jensen, C., Bonini, S., Bousquet, J., BousquetRouanet, L., Bousquet, P. J., Bresciani, M., Bruno, A., Burney, P., Canonica, G. W., Darsow, U., Demoly, P., Durham, S., Fokkens, W. J., Giavi, S., Gjomarkaj, M., Gramiccioni, C., Haahtela, T., Kowalski, M. L., Magyar, P., Muraközi, G., 
Orosz, M., Papadopoulos, N. G., Röhnelt, C., Stingl, G., Todo-Bom, A., von Mutius, E., Wiesner, A., Wöhrl, S. and Zuberbier, T. (2009). GA2LEN skin test study I: GA2LEN harmonization of skin prick testing: novel sensitization patterns for inhalant allergens in Europe, Allergy, 64(10), 1498-1506, doi:10.1111/j.1398-9995.2009.02093.x,

Hirst, J. M. (1952). An automatic volumetric spore trap, Annals Applied Biology, 39, 257-265

Jones, A. M. and Harrison, R. M. (2004). The effects of meteorological factors on atmospheric bioaerosol concentrations

- a review, Science of the Total Environment., 326(1-3), 151-180

Juozaitis, A., Willeke, K., Grinshpun, S.A. and Donnelly, J. (1994). Impaction onto a Glass Slide or Agar versus

Kim, K.-H., Kabir, E. and Jahan, S. A. (2017). Airborne bioaerosols and their impact on human health, Journal of

Lee, H., Lee, S., Lee, H.M., Kim, S., Kim, Y.P. and Kang, H. (2010). Identification of airborne bacterial and fungal community structures in an urban area by T-RFLP analysis and quantitative real-time PCR, Science of the Total Environment, 408 (6), pp. 1349-1357

Marchetti, P., Pesce, G., Villani, S., Antonicelli, L., Ariano, R., Attena, F., Bono, R., Bellisario, V., Fois, A., Gibelli, N., Nicolis, M., Olivieri, M., Pirina, P., Scopano, E., Siniscalco, C., Verlato, G. \& Marcon, A. (2017), Pollen concentrations and prevalence of asthma and allergic rhinitis in Italy: Evidence from the GEIRD study, Science of The Total Environment, 584-585:1093-1099. doi: 10.1016/j.scitotenv.2017.01.168 invasive angiosperm, American Journal Botany, 96(9), 1703-1711, doi:10.3732/ajb.0800407, 2009. Mudway, I.S., Langrish, J.P., Couderc, S., Blomberg, A., and Sandström, T. (2014), Assessment of the capacity of vehicle cabin air inlet filters to reduce diesel exhaust-induced symptoms in human volunteers, Environmental Health 13 (1) pp. 16. measurements with Pitot tubes and GNSS receivers mounted on consumer-grade unmanned aerial vehicles applicable in meteorological studies? Environmental Monitoring and Assessment, 189(9), 431, doi:10.1007/s10661-017-6141-x, 2017. 
Park, J.H., Yoon, K.Y., Noh, K.C., Byeon, J.H. \& Hwang, J. (2010), Removal of PM2.5 entering through the ventilation duct in an automobile using a carbon fiber ionizer-assisted cabin air filter, Journal of Aerosol Science, 41, (10), pp. 935943.

431

Pollock, J., Shi, L. \& Gimbel, R.W. (2017), Outdoor Environment and Pediatric Asthma: An Update on the Evidence from North America", Canadian Respiratory Journal, 2017, pp. 1-16.

Radosevich, J.L., Wilson, W.J., Shinn, J.H., DeSantis, T.Z. \& Andersen, G.L. (2002), Development of a high-volume aerosol collection system for the identification of air-borne micro-organisms, Letters in Applied Microbiology, 34, (3), pp. 162-167

Savage, D., Barbetti, M. J., MacLeod, W. J., Salam, M. U. and Renton, M.(2012) Mobile traps are better than stationary

traps for surveillance of airborne fungal spores, Crop Protection., 36, 23-30, doi:10.1016/J.CROPRO.2012.01.015.

Schrader, C., Schielke, A., Ellerbroek, L. and Johne, R. (2012), PCR inhibitors - occurrence, properties and removal.

Sikoparija, B., Skjøth, C. A., Celenk, S., Testoni, C., Abramidze, T., Alm Kübler, K., Belmonte, J., Berger, U., Bonini, M., Charalampopoulos, A., Damialis, A., Clot, B., Dahl, Å., de Weger, L. A., Gehrig, R., Hendrickx, M., Hoebeke, L., Ianovici, N., Kofol Seliger, A., Magyar, D., Mányoki, G., Milkovska, S., Myszkowska, D., Páldy, A., Pashley, C. H., Rasmussen, K., Ritenberga, O., Rodinkova, V., Rybníček, O., Shalaboda, V., Šaulienė, I., Ščevková, J., Stjepanović, B., Thibaudon, M., Verstraeten, C., Vokou, D., Yankova, R. and Smith, M. (2017). Spatial and temporal variations in airborne Ambrosia pollen in Europe, Aerobiologia., 33(2), 181-189, doi:10.1007/s10453-016-9463-1,

451

452

453

454

455

456

457

458

459

Skjøth, C. A., Damialis, A., Belmonte, J., De Linares, C., Fernández-Rodríguez, S., Grinn-Gofroń, A., Jędryczka, M., Kasprzyk, I., Magyar, D., Myszkowska, D., Oliver, G., Páldy, A., Pashley, C. H., Rasmussen, K., Satchwell, J., Thibaudon, M., Tormo-Molina, R., Vokou, D., Ziemianin, M. and Werner, M. (2016). Alternaria spores in the air across Europe: abundance, seasonality and relationships with climate, meteorology and local environment, Aerobiologia., 32(1), 3-22, doi:10.1007/s10453-016-9426-6,

Skjøth, C. A., Ørby, P. V, Becker, T., Geels, C., Schlünssen, V., Sigsgaard, T., Bønløkke, J. H., Sommer, J., Søgaard, P. and Hertel, O.: Identifying urban sources as cause of elevated grass pollen concentrations using GIS and remote sensing, Biogeosciences, 10(1), 541-554 L., Majkowska-Wojciechowska, B., Rybnicek, O., Thibaudon, M., Gehrig, R., Bonini, M., Yankova, R., Damialis, A., Vokou, D., Gutierrez Bustillo, A. M., Hoffmann-Sommergruber, K. and van Ree, R. (2014). Geographic and temporal variations in pollen exposure across Europe, Allergy, 69(7), 913-923

Snyder, A.P., McClennen, W.H., Dworzanski, J.P. \& Meuzelaar, H.L. (1990), Characterization of underivatized lipid biomarkers from microorganisms with pyrolysis short-column gas chromatography/ion trap mass spectrometry, Analytical chemistry, 62, (23), pp. 2565-2573.

Tolchinsky, A.D., Sigaev, V.I., Varfolomeev, A.N., Uspenskaya, S.N., Cheng, Y.S. and Su, W. (2011), Performance evaluation of two personal bioaerosol samplers, Journal of Environmental Science and Health, Part A, 46, (14), pp. 16901698 
475 Torkko P, Katila M. and Kontro (2003). Gas-chromatographic lipid profiles in identification of currently known slowly

476 growing environmental mycobacteria. Journal of Medical Microbiology. 52(4):315-323 doi:10.1099/jmm.0.05113-0

477

478

479

Werchan, B., Werchan, M., Mücke, H.-G., Gauger, U., Simoleit, A., Zuberbier, T. and Bergmann, K.-C. (2017) Spatial

480

distribution of allergenic pollen through a large metropolitan area, Environmental Monitoring and Assessment, 189(4), 169, doi:10.1007/s10661-017-5876-8,

481

482

483

West, J.S. and Kimber, R.B.E. (2015), Innovations in air sampling to detect plant pathogens, Annals of Applied Biology, 166, (1), pp. 4-17.

484

485

Willers, C., Jansen van Rensburg, P.J. and Claassens, S. (2015), Microbial signature lipid biomarker analysis - an 486

Wong, L.T., Mui, K.W., Cheung, C.T., Chan, W.Y., Lee, Y.H. \& Cheung, C.L. (2011), In-cabin Exposure Levels of Carbon Monoxide, Carbon Dioxide and Airborne Particulate Matter in Air-Conditioned Buses of Hong Kong, Indoor and Built Environment, 20, (4), pp. 464-470.

492

$6 \quad$ Tables and Figure legends

494 Table 1. Total protein $\left(\mathrm{mg} \mathrm{mL}^{-1}\right)$ extracted from used car filters.

\begin{tabular}{|l|rr|}
\hline Filter & Total protein $\mathrm{mg} \mathrm{mL}^{-1}(2 \mathrm{dp})( \pm$ SD) & \\
\hline A & $0.10( \pm 0.06)$ \\
\hline B & $0.67( \pm 0.13)$ \\
\hline C & $1.47( \pm 0.01)$ \\
\hline D & $1.37( \pm 0.01)$ \\
\hline E & $0.42( \pm 0.01)$ \\
\hline F & $0.91( \pm 0.11)$ \\
\hline
\end{tabular}

495

496

Fig. 1 Number of colony forming units from total viable counts and fungal colonies on two road driven car filters. Error bars represent SEM across both filters $(n=3)$

498

Fig. 2 Inhibitor removal for qPCR of birch pollen isolated from 'on-road' car cabin filters. Error bars represent SEM across all six filters $(\mathrm{n}=18)$

500 Fig. 3 Inhibitor removal for qPCR of eukaryotic DNA isolated from 'on-road' car cabin filters. Error bars represent SEM 501 across all six filters $(n=18)$ 